Vitamin D and Myocardial Infarction

SIR,-Professor V. Lindén (14 September 1974 , p. 647) reponts a study of vitamin D consumption in different Norwegian population groups, in particular persons who had qualified for a disability pension because of myocardial infarction, angina pectoris, or degenerative joint disease. From his results Professor Lindén concludes that a high intake of vitamin $D$ is a risk factor in the occurrence of myocardial infarction and that $30 \mu \mathrm{g}$ a day is the critical level. He found that the chief source of the vitamin D consumed was fish liver, which is an impontant item in the diet of the population providing the subjects for the study. The logic underlying the conclusions reached by Professor Lindén on the basis of his data is fundamentally unsound, for his findings permit of other possible explanations.

It is true that Professor Lindén has convincingly shown the stated vitamin $\mathrm{D}$ consumption to be greater in the myocardial infarction group than in the controls, but he has not shown that this higher intake is responsible for the higher incidence of the disease. On the contrary, it is conceivable that the higher incidence and the higher intake of vitamin D had a common cause-for example, dietary habits-possibly arising from a difference in the living standard of the groups.

As mentioned above, the excessive intake of vitamin $\mathrm{D}$ was chiefly due to the consumption of large amounts of fish liver. The observed relationship may thus very well be not between vitamin $\mathrm{D}$ and the disease but hetween fish liver and the disease, sinoe fish liver contains more than just vitamin D for example, heavy metals.

The completion of a questionnaire on intake of medicines and dietary habits may presumably yield different results-even though the intake may be the sameaccording to, for example, a difference in morbidity between the groups. This retrospective study thus has serious shortcomings. This is the more unfortunate because the results might be taken by the uninitiated as support for propaganda against vitamins. - We are, etc.,

OLOV LINDAHI

University Hospital,
Linköping, Sweden LARS LINDWALI

\section{Xanthinuria as a Cause of Hypouricaemia in Liver Disease}

SIR,-In 1967 we treated a patient with a xanthine stone in the bladder. In a biochemical study of 30 members of the partient's family we found three more cases of xanthinuria. None presented clinical symptoms. ${ }^{2}$

In August 1974 we re-examined a brother of the proband. He had a history of alcoholism but his previous biochemical study had shown no xanthinuria. At that time his serum urate level was $0.26 \mathrm{mmol} / \mathrm{l}(4.4 \mathrm{mg} / 100 \mathrm{ml})$, serum oxypurines $1.8 \mathrm{mg} / 1$, and urinary urate $2.3 \mathrm{mmol} / 24 \mathrm{~h}(392 \mathrm{mg} /$ $24 \mathrm{~h}$ ). No urinary oxypurines were found on paper $24 \mathrm{~h}$ ). No urinary oxypurines were found on paundice in 1971 he had progressively developed ascites, oedema, epistaxis, and hepatic encephalopathy. The clinical and biochemical picture was that of liver cirrhosis without haemochromatosis. He liver cirrhosis without haemochromatosis. He
refused a liver biopsy. He also had persistent hypouricaemia (serum urate $0.049 \mathrm{mmol} / 1(0.84 \mathrm{mg} /$ $100 \mathrm{ml}$ )) and hypouricosuria (urinary urate 0.3 $\mathrm{mmol} / 24 \mathrm{~h}(50.5 \mathrm{mg} / 24 \mathrm{~h})$ ). His serum oxypurines (xanthine plus hypoxanthine) were $5.6 \mathrm{mg} / \mathrm{l}$. Xanthine oxidase was not found in the blood cells. The urinary excretion of purines was xanthine $368 \cdot 7 \mathrm{mg} / 24 \mathrm{~h}$ and hypoxanthine $67 \cdot 7 \mathrm{mg} / 24 \mathrm{~h}$.

Hypouriœemia in liver diseases has been attributed to an increase in renal uric acid clearance. ${ }^{34}$ In our case the hypouricaemia was associated with xanthinuria, suggesting that liver insufficiency may unmask a partial defect of xanthine oxidase in people genetically conditioned even though they have not previously shown any overt biochemical abnormality. Therefore in cases of hypouricaemia associated with liver disease xanthinuria should be looked for both in the patient and among members of the patient's family.-We are, etc.,

H. J. Castro MEndoza J. M. CASTRILLO
M. FRUTOS

L. Cifuentes Delatte

Unidad Metabólica and Departmento de Biochímica, Madrid, Spain

1 Castro Mendoza, H. J., Cifuentes Delatte, L., and Rapado,

2 Rapado, 341 ., Castro Mendoza, H. J. and Cifuentes Delatte, L., in Urinary Calculi, ed. L. Cifuentes, A. Rapad

3 Matz, R., Christoudoulou, J., and Vianna, N., New York State fournal of Medicine, 1969, 69, 1312.

Michelis, M. F., et al., Archives of Internal
Medicine, 1974, 134, 681.

\section{A Health District Courier Service}

SIR,-Mr. I. J. Y. Cook (10 May, p. 335) raises a subject that has wider applications. With rising postal charges the expenditure on postage by family practitioner committees and the 10000 general practice units that communicate with one another each week will certainly be between $£ 500000$ and $£ 1 m$ this year.

One way of cutting down these costs drastically is to use local hospitals as reception stations for packets to and from local general practitioners and the F.P.C.s. Each area health authority already has its own courier services between its various units, and the F.P.C. is now part of the authority. We have used a local hospital in this way for some time and the speed of deliveries has been improved.-I am, etc.,

Beckenham, Kent,

JOHN FRY

Tolamolol in Treatment of Angina Pectoris

SIR,-In their account of a double-blind comparative trial of tolamolol, propranolol, practolol, and placebo in the treatment of angina pectoris Dr. Graham Jackson and his colleagues (29 March, p. 708), report that four patients reacted adversely when treated with tolamolol, one developing a severe bradycardia, two sustaining a cardiac infarct, and one developing crescendo angina. Three of these patients subsequently died.

The authors quote the expected yearly montality rate to be about $4 \%$ and argue that as the trial "lasted 10 months with each patient" they believe that these deaths represent the natural history of angina pectoris. However, they later state that "the total duration of the trial was 10 months" and it would appear from the protocol that each patient was followed for only six months and that during that time he was on tolamolol for only eight weeks. Furthermore, only 47 patients entered the trial. This would give an annual incidence of severe advense reaction on tolamolol of $55.3 \%$ and a related annual mortality of $41.5 \%$, which is markedly in excess of the expected yearly montality rate for angina peotoris.

Surely, in a trial of a new drug, patients developing possible adverse reactions should not be excluded from the analysis, particularly if the possible advense reaction subsequently leads to death. Fnom the information contained in the article it is my opinion that the conclusion reached, for reasons already given, is very misleading.-I am, etc.,

Haywards Heath, Sussex

CHRISTOPHER GOOD

Radioactive Bromide Partition Test and Mumps Meningoencephalitis

SIR,-The radioactive bromide partition test is a valuable additional aid in the differential diagnosis of lymphocytic meningitis, particularly in the early diagnosis of tuberculous meningitis when the bacillus is not demonstrable in the cerebrospinal fluid and sugar levels ane equivocal. The critical serum:C.S.F. ratio is 1.6 . In tuberculous meningitis the ratio falls below this level and is a strong indication for starting specific treatment at once. In nontuberculous lymphocytic meningitis higher values between 2 and 3 are found. Mandal et al. ${ }^{1}$ found the test $100 \%$ accurate in four tuberculous and 15 non-tuberculous patients.

Early this year a boy aged 7 years was admitted to hosoital with signs of meningitis. Relevant features in the history were a recent attack of chickenpox, a recent addition to the household of a puppy currently sick and under treatment by a veterinary surgeon, and the occurrence of mumps in the boy's school. High fever continued for seven days. There was a continuing pleocytosis $(90 \%$ lymphocytes) in the C.S.F for 15 days. Though C.S.F. protein and sugar were within normal limits our experience is that a normal sugar content does not exclude tuberculous meningitis. ${ }^{2} X$-ray examination of the chest and the Mantoux test were negative. Laboratory tests excluded leptospirosis, toxoplasmosis, and infectious mononucleosis. Eight days after admission the bromide partition test showed a ratio of 1.4 -that is, within the range of tuberculous meningitis. Electroencephalography showed focal disturbances in the left mid-temporal zone reported as not incompatible with a meningitic process but unlikely to be associated with a space-occupying lesion. Tubercle bacilli were not seen in the C.S.F., there was no evidence of tuberculosis elsewhere, nor was there a family history of tuberculosis. Furthermore, there was the history of contact with mumps. Mumps meningitis may be distinguished from other forms of viral meningitis by prolonged fever (in this case 12 days) and higher cell counts in the C.S.F. For these reasons antituberculosis drugs were not prescribed in spite of the results of the bromide partition test. Subsequent results of paired sera showed a rise in antibody titre $(5 / 512)$ to mumps $S$ virus, indicating a recent infection. No tubercle bacilli were grown on culture nor were any viruses isolated in rhesus monkey kidney tissue. A final E.E.G. showed a normal record. The patient made an uneventful recovery.

One case of mumps meningoencephalitis does not invalidate the bromide partition test. It is a reminder that the results of laboratory aids must not be considered in isolation from clinical and pathological observations when a decision has to be taken 
whether to begin long-term antituberculosis therapy. - I am, etc.,

Ruchill Hospital,

JAMES H. LAWSON

1 Mandal, B. K., et al., British Medical fournal,

1972, 4, 413.
79an, R. J., British Medical fournal, 1972, 4,

\section{Drug-precipitated Acute Attacks of Gout}

SIR,-Though there has been little discussion about drug precipitation of acute attacks of gout, it is known that diuretics such as hydrochlorothiazide, ethacrynic acid, and frusemide induce hyperuricaemia and thus precipitate acute attacks. ${ }^{1}$ Among the other drugs implicated are pyrazinamide, niacin pempidine, alcohol, mecamylamine, and salicylates if the dose is less than $4 \mathrm{~g}$ per day. ${ }^{2}$ It would be of interest, therefore, to add a little to this list, seeing that the incidence of gout in Asians is muoh higher than was formerly thought. ${ }^{2}$

A patient aged 40 , of Chinese origin, who had been suffering from gout for the past five years with a serum urate level of $0.6 \mathrm{mmol} / \mathrm{l}(10 \mathrm{mg} / 100$ $\mathrm{ml}$ ) recently presented with an acute attack of gout after taking a hypnotic the night before. The patient was not stabilized on any drug, but had been relatively free from acute attacks and was familiar with the precipitating factors in his case. Regular estimations of the serum urate level once a week after this episode revealed fluctuations, depending upon his activities, from 0.32 to 0.74 $\mathrm{mmol} / 1(5.4$ to $12.5 \mathrm{mg} / 100 \mathrm{ml})$. The threshold for an acute attack was at about $0.54 \mathrm{mmol} / 1(9 \mathrm{mg} / 100$ $\mathrm{ml}$ ).

During the study period of three months the patient presented with an acute attack on five occasions after taking nitrazepam $10 \mathrm{mg}$ and had a serum urate level of $0.6-0.7 \mathrm{mmol} / 1(10-12 \mathrm{mg} / 100$ $\mathrm{ml}$ ). Diazepam $5 \mathrm{mg}$ and chlordiazepoxide $15 \mathrm{mg}$ also precipitated acute attacks. His treatment was then changed to Mandrax (methaqualone $250 \mathrm{mg}$ and diphenhydramine $25 \mathrm{mg}$ ) but he again suffered an acute attack with raised serum urate levels. All attacks were successfully controlled with colchicine $0.6 \mathrm{mg}$ and niflumic acid $250 \mathrm{mg}$ six-hourly.

It seems possible that hypnotic drugs can now be included into the list of medications which can precipitate acute attacks of gout, a list which physicians should be well aware of.-I am, etc.

Department of Pharmacology,

Chan OnN Leng Faculty of Medicine,

Kuala Lumpur

1 Healey, L. A., Majid, G. J., and Decker, J. L., New England fournal of Medicine, 1959, 261,
1358. . B. S., Far East Medical fournal, 1967, 3, 406 .

\section{Pseudocyanosis Neonatorum}

SIR,-I should like to report a case of pseudocyanosis in the newborn-pseudocyanosis neonatorum.

The patient, a Caucasian male weighing $3.62 \mathrm{~kg}$, was born to a 23-year-old primigravida of good health and barely adequate pelvis. At delivery the infant presented the appearance of gross cyanosis affecting the face and lips and this persisted despite a lusty and continuous cry.

The diagnosis of pseudocyanosis was apparent for reasons similar to the case of pseudocyanosis in an adult reported by Dr. N. G. Gold (13 July 1974, p. 119) in that there were no other features of cardiorespiratory disease and the simulated cyanosis involved neither the limbs nor the mucous membranes within the mouth. The cause was thought to be facial contusion consequent to a degree of cephalopelvic disproportion, and this was subsequently confirmed by the characteristic evolution of colour whioh the face underwent.-I am, etc.

Kettering and District General Hospital,

M. NELSON

Kettering, Northant

\section{"Nasal FEV"}

SIR,-Dr. J. Morrison-Smith and his colleagues (3 May, p. 255) state that "no completely satisfactory and simple measure of changes in nasal airway is available." Conscious of the need for a simple method of demonstrating changes we developed a "blockage index." This measurement correlates very well with nasal airways resistance as measured using more complex apparatus. The peak expiratory flow rate (PEFRo) is measured in the usual way using a Wright peak flow meter, after which the mouthpiece is replaced by a semirigid rubber face-mask and the patient breathes out forcibly through his nose, keeping his mouth firmly closed. This measurement is the peak expirator' flow rate through the nose $\left(P^{\prime} E F R_{n}\right)$. The blockage index is then: $\left(\right.$ PEFR $_{0}$ PEFR $\left._{n}\right) \div$ PEFR $_{\text {. }}$

Unlike the "nasal FEV" described by Dr. Morrison-Smith and his colleagues the blockage index is independent of variations in the lower airways and is therefore valid for use before and after allergen challenge. -We are, etc.

GEOFFREY TAYLOR D. L. J. FrEed Department of Bacteriology and Virology,

1 Taylor, G., MacNeil, A. R., and Freed, D. L. J., Fournal of .1llergy and Clinical Immunology,
$1973,52,193$.

\section{Emigration of Doctors}

SIR,-The truth of Dr. B. Senewiratne's two articles on medical emigration from developing countries (15 March, p. 618, and 22 March, p. 669) seemed so self-evident that I did not think of writing to endorse them until I read the dissenting letters from Drs. N. R. E. Fendall and A. J. R. Waterston (26 April, p. 190). Both dealt with the two important and interlinked questions of (1) tailoring the medical course in developing countries to the specific problems of those countries and (2) the use of paramedical workers to do routine tasks usually done in industrialized countries by doctors, so as to free the doctor in developing countries for vital educative and administrative work.

Over the past few years these two questions, or rather convening conferences on them and writing papers about them, have been one of the most remarkable growthpoints in tropical medicine. There have been little in the way of tangible results because centain facts are always ignored. I would like to outline some of them, but for considerations of space I must be brief and dogmatic.

(1) Paralleling the decline in the morale, discipline, and output of our Health Service has been a similar falling-off in developing countries. This matter is never discussed.
As in our own Health Service, it is so much more acceptable to all parties to suggest "reorganization."

(2) It is accepted by the "reformers" that doctors are reluctant to go to rural areas. To replace the dootor they invent an Ideal-the paramedical worker who is only too delighted to do so. Unfortunately he does not exist. Having been a district medical officer myself I can attest that paramedical workers spend just as much of their time as doctors agitating to be posted back to the capital or sent on another course. Replacing sullen doctors by sullen paramedical workers achieves nothing.

(3) Anybody who has seen, or experienced himself, the extraordinary habits an isolated doctor can get into must appreciate how much more easily this can happen with a lesser-trained worker.

(4) "Adjusting" the medical course means lowering the standard (see George Orwell's Animal Farm and 1984). This could be argued about for hours. I do not believe the "reformers" consciously desire to lower the standards, but that is where their highminded endeavours lead. For example, a professor of clinical sciences in a developing country recently told me he did not want his registrars taking even such a relatively trivial examination as the M.R.C.P.(U.K.) because it was "not relevant to the medicine they had to practise." All it tests, after all, is a basic competence in physical signs and a general knowledge of internal medicine.

The structure the "reformers" are searching for, as I understand it, is a pyramid with the doctor at the apex and his paramedical workers ranged below him, each doing his job to the best of his ability, reponting upwards the problems he cannot solve, and receiving in return a continuous flow of advice, encouragement, and education from those above him on the pyramid who know more than he does. I am happy to tell the "reformers" that their search is at an end. This very system was developed over a century by the Colonial Medical Service. There must be some survivors of the service still alive, though they would be well into their late thirties or even older by now. Could not some of them be invited to the next conference-or the next half-dozen - lest the secret die with them?-I am, etc.,

M. P. WHITE

Thornbury, Glos

\section{Reversible Infertility in Male} Coeliac Patients

SIR,-It was interesting to read of the two additional cases of reversible subfertility in male patients with coeliac disease after treatment with a gluten-free diet (10 May, p. 316), though the improvement in the seminal fluid analyses reported was hardly impressive. However, it was surprising that the authors had not checked previous publications on this subject.

In the B.M.F. as long ago as $1962^{1}$ the case was reported of a youth of $18 \frac{1}{2}$ in 1952 with coeliac disease and infantilism, whose normal adult development was stimulated with androgens while on an ordinary diet until 1953. When fully virilized in 1954 he had azoospermia, and a previous testicular biopsy had shown only tubules containing Sertoli cells, with few spermatogonia and 